\title{
Organic contaminants in marine mammals
}

\author{
ANNAMALAI SUBRAMANIAN*, SHINSUKE TANABE** and SUBRAMANIAN KARUPPIAH*
}

${ }^{*}$ Centre of Advanced Study in Marine Biology, Annamalai University, India, ${ }^{* *}$ Centre for Marine Environmental Studies, Ehime University, Japan.

SUMMARY : Organic contaminants accumulated in cetaceans reflect the levels in the ambient environment and / or their food. Recent research pointed out the possibilities of using the residue levels in the bodies of long-life marine animals in determining the life history like migration pattern, age and growth, reproductive history etc. The levels of the organic contaminants such as HCHs, DDTs, PCBs, HCB, CHLs, BTs, TCPMe and TCPMOH in cetaceans closely relates to the characteristic mobility of the compounds. The highly mobile compounds such as $\mathrm{HCHs}$ were higher in cold and temperate water animals suggesting the atmospheric transport from tropical source to northern sinks, whereas DDTs were higher in tropical water species, indicating its less movable nature. PCBs, CHLs and HCB were showing a more or less similar pattern to $\mathrm{HCHs}$, whereas TCPMe and TCPMOH showed a latitudinal distribution similar to DDTs. Such complex phenomena were discussed.

\section{KEYWORDS: organic contaminants; marine mammals; global distribution}

\section{INTRODUCTION}

The most recent comprehensive surveys on global contamination by persistent organic chemicals revealed that large qualities of organochlorines used in the tropical regions are released into the atmosphere and redistributed on a global scale ${ }^{1,2)}$. Since these chemicals finally reach the oceans, the effects of such chemicals on the marine mammals, the top predator in the marine food chain, are of great concern ${ }^{3,4)}$.

The marine food chain has a high capacity to amplify contaminants despite low reside levels in water ${ }^{5}$. Unlike heavy metals, the man-made organic contaminants do not occur naturally. Even through the use of these compounds started only recently, most of them are now ubiquitous and highly bioaccumulatives. Concentrations in marine mammals depend on various environmental, ecological and physiological parameters.

\section{CHARACTERISTIC MOBILITY OF ORGANIC CONTAMINANTS}

Many of the organic contaminants, such as HCHs (Hexachlorocyclohexane), DDTs (Dichlorodiphenyltrichloroethane), PCBs (Polychlorinated biphenyls) HCB (Hexachloro benzene) CHLs (Chlordanes), BTs (Butyl tin compounds) TCPMe [(Tris 4 chlorophenyl) methane], TCPMOH [(Tris 5 chlorophenyl) methanol] and so on have been produced in large quantities and find widespread use. Several of the developed nations have banned the usage of some of these chemicals and imposed restrictions on the use of some other toxic chemicals. But, most of the under-developed and developing nations, situated mostly in the tropical belt, prefer to use cost-effective, wide spectrum and versatile chemicals.

The developed nations which banned the use of these chemicals, still manufacture and export them, only to get the boomerang of the contamination via various means. In an Indian estuary Takeoka et al. ${ }^{6}$ found that, inspite of large usage, the localized contamination of $\mathrm{HCHs}$ is low; instead more rapid contamination is advancing on global terms due to the 'long-range atmospheric transport' of residues from the 'point-source' areas (Fig.1).

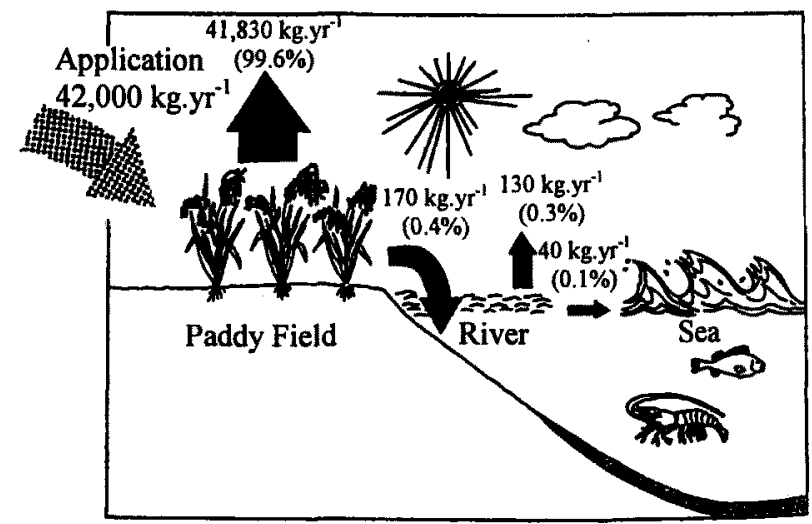

Fig. 1. Schematic representation of the flux of $\mathrm{HCHs}$ in Vellar river watershed, South India).

Most of these chemicals mentioned above are volatile enough to evaporate at ordinary environmental temperatures existing at the tropical areas. Depending 
upon the type of the chemical and its vapour pressure, evaporation, condensation and deposition occur at various places of the earth leading to global partitioning. Because of this effect, the concentrations of such chemicals may rise even in the remote parts of the world, such as Arctic and Antarctic ${ }^{7}$.

\section{ORGANIC CHEMICALS IN CETACEANS}

Small cetaceans accumulate very high amounts of persistent chemicals through feeding ${ }^{5)}$ and also they can excrete and transfer large quantities of these pollutants over generation through lactation ${ }^{8-11)}$. There has been some successful attempts for using cetaceans as indicators of global pollution by organochlorines $^{12)}$. It was also found that by estimating the levels of certain organic chemicals such as DDTs and PCBs in the fat tissues of animals, certain biological characteristic such as population identification, migratory pattern etc. can be determined.

The persistent organic chemicals, such as chlorinated hydrocarbons have been used as chemical traces for elucidating some ecological aspects of marine mammals by several authors ${ }^{13-15}$.

Generally, in all the available literature the females of marine mammals have been reported to have considerably lower concentrations of organic chemicals than males, ${ }^{8,10,13)}$ which might have resulted obviously via lactational transfer.

When the male-female differences of DDE and PCBs have been assessed among specimens of Dall's porpoises (Phocoenoides dalli) (Fig. 2), a decrease in the concentrations of both chemicals was observed in females with age after about 3 years which was close to the sexual maturity age.

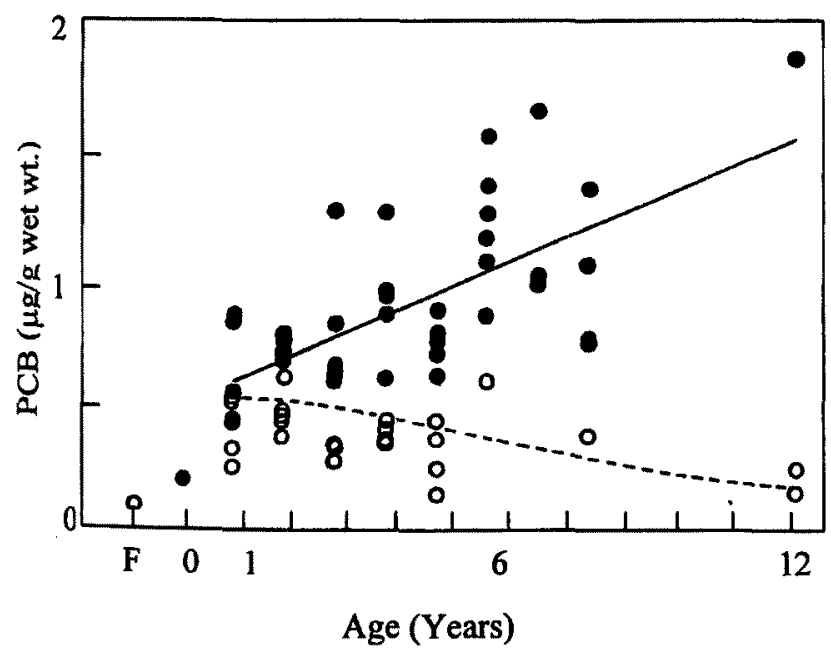

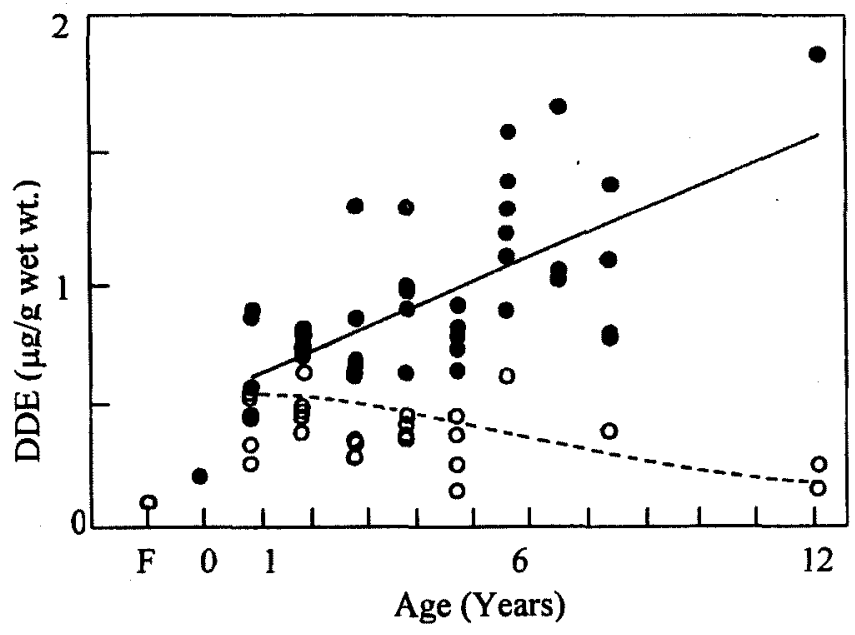

Fig. 2. Relationship between age and concentration of PCBs and DDE in male (•) and female (o) Dalli-type Dall's porpoises collected from northwestern North Pacific. ${ }^{14)}$

Same trend of male - female differences in organochlorine concentrations was observed earlier by Tanabe et al. ${ }^{9)}$ in striped dolphins. Such type of differences can very well be used in the determination of the age, age of attaining sexual maturity, reproductive status of the organism, migratory pattern etc. ${ }^{15)}$ Further, using the fact that lower chlorinated biphenyls are transferred more through lactation, the detailed reproductive history of the animal could be traced. The inference drawn by these observations agrees fairly well with the ecological observations of many authors. ${ }^{16,17)}$ Same type of observations were made in several species of marine mammals like short -finned pilot whale ${ }^{18)}$ and Baird's Beaked whale. ${ }^{15)}$

The previous research works used the organic chemicals as chemical tracers to trace the life - history of long-life marine animals. Research work in the last decade on the levels of many other chemicals like PCBs, HCB, CHLs, HCHs, TCPMe, TCPMOH, etc. in the bodies of these animals were used to sort-out and answer certain querries in the global environmental pollution status of these chemicals by using the concentrations of the same chemical in the biota. For example, in an attempt of our group ${ }^{19)}$ in elucidating the global distribution and toxicological impacts of PCBs on cetaceans, we found that the total PCB concentrations in these animals from temperate and cold waters were higher than those in cetaceans from tropical regions, reflecting serious marine pollution by PCBs in industrialized countries in the northwestern North Pacific. 
In a related work done earlier, ${ }^{20)}$ relatively high DDT concentrations were found in tropical species of cetaceans, which was attributed by the authors as due to the current usage of DDT in the tropics, and the less movable nature of this compound by atmospheric transport. At the same time the $\mathrm{HCHs}$ levels in animals inhabiting cold and temperate waters were higher than those inhabiting tropical waters, suggesting that they were perhaps reflective of atmospheric transport from the tropical source to the high latitude areas in the northwestern North Pacific. A similar pattern was also observed in PCBs, CHLs and $\mathrm{HCB}$, suggesting the ongoing discharge of the compounds from mid-latitudes as well as those originating in tropical regions (Fig. 3).
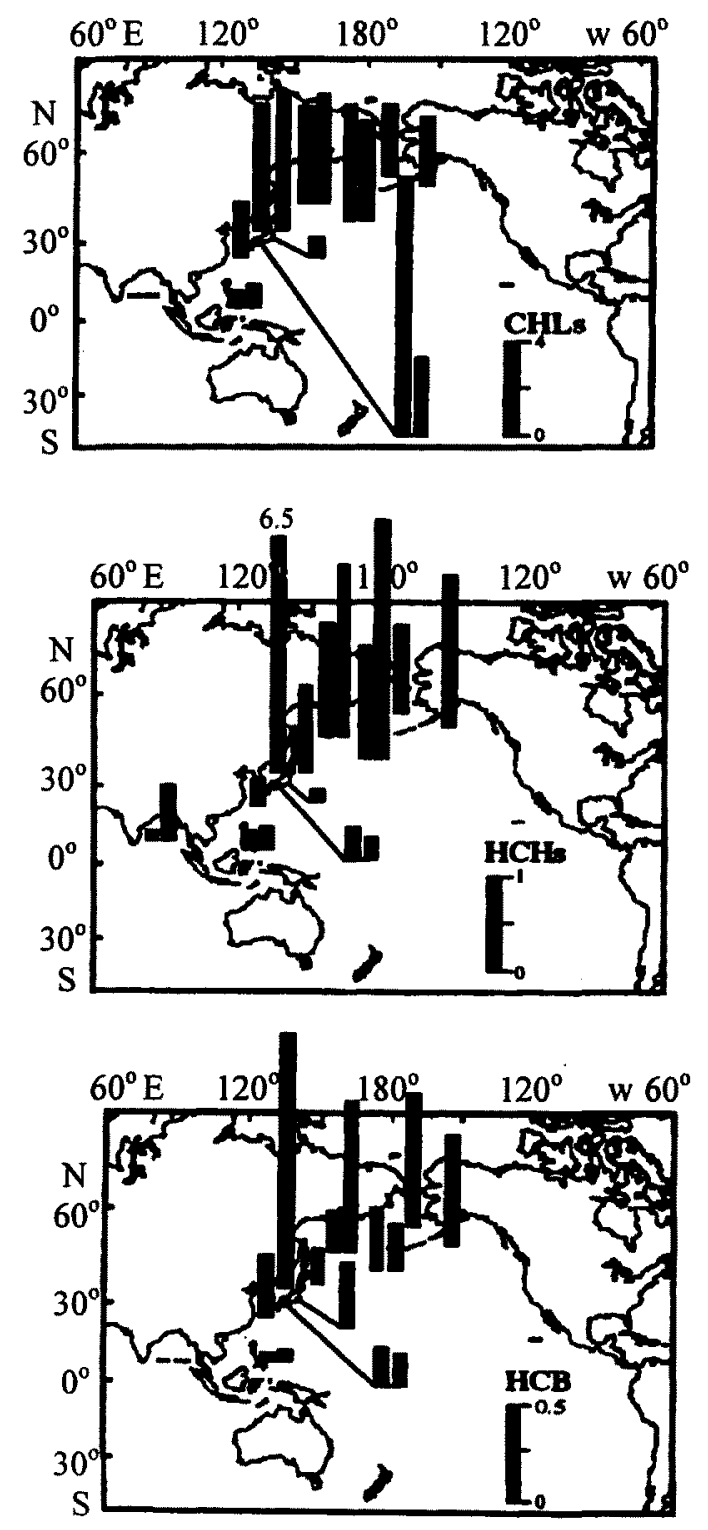

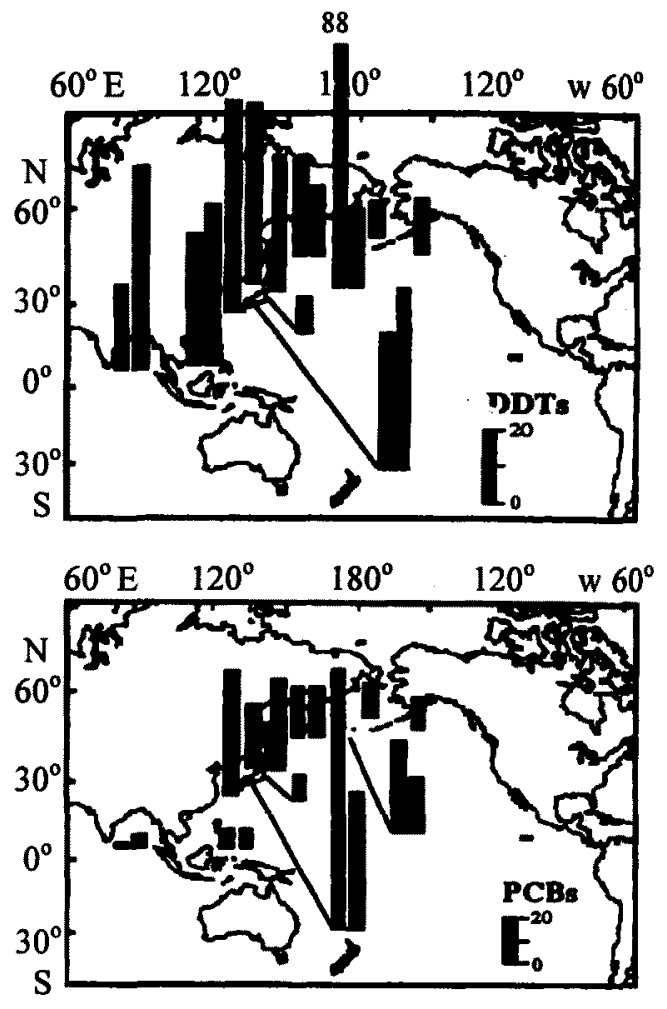

Fig. 3. Distribution of DDTs, PCBs, HCHs, CHLs and HCB residue levels $(\mu \mathrm{g} / \mathrm{g}$ wet $w t)$ in odontoceti animals from various locations of the North Pacific, Indian Ocean and nearby seas ${ }^{20}$.

Minh et al. found that TCPMe and TCPMOH, having similar structures to pesticide DDT and dicofol, respectively occur as micro-contaminants in cetaceans. They also found that the latitudinal distribution of these two chemicals in cetaceans from North Pacific and Asian coastal waters was similar to that of DDTs, suggesting the less transportable nature of TCPMe and TCPMOH in the marine environment similar to that of DDTs.

Another important and interesting organic chemical from the global contamination point of view are the butyltin compounds (BTs). Elevated BTs residues were found in the coastal species of marine mammals than the off shore species. Interestingly, mammals inhabiting waters of developed nations were found to contain higher BTs concentrations than those collected from waters to developing countries. ${ }^{21)}$

Measuring the levels of organic contaminants in the environmental samples is rather tedious considering their low concentrations. But all the above chemicals gets accumulated to very high concentrations in various tissues and organs of cetaceans, and hence can be successfully used to delineate the latitudinal distribution of such compounds. 


\section{REFERENCES}

1. Iwata H, Tababe S, Sasaki N, Tatsukawa R. Distribution of Persistent organochlorines in oceanic air and surface seawater and the role of ocean on their global transport and fate. Environ. Sci. Technol. 1993; 27 : 1080-1098.

2. Tanabe S, Iwata $H$, Tatsukawa $R$. Global contamination by persistent organochlorines and their ecotoxicological impact on marine mammals. The Sci. Total Environ. 1994 ; 154 : 163-177.

3. Tanabe S, Tatsukawa, R. Persistent organochlorines in marine mammals. In Jones $\mathrm{KC}$ (ed) Organic contaminants in the environment. Elsevier, New York, 1991, pp. 275-289.

4. Colborn T, Smolen MJ. Epidemiological analysis of persistent organochlorine contaminants in cetaceans. Rev. Environ. Cotam. Toxicol. 1996; $146: 91-171$.

5. Tanabe S, Tanaka H, Tatsukawa R. Polychlorobiphenyls, $\mathrm{DDDT}$ and hexachloro-cyclohexane isomers in the western North Pacific ecosystem. Arch. Environ.Contam. Toxicol. 1984; 13 : 731738.

6. Takeoka H, Ramesh A, Iwata H, Tanabe S, Subramanian AN, Mohan D, Magendran A, Tatsukawa R. Fate of the insecticide $\mathrm{HCH}$ in the tropical coastal area of South India. Mar. Pollut.Bull. 1991; 6 : 290- 297.

7. Wania F, Mackay D. Tracking the distribution of persistent organic pollutants. Environ. Sci. Techol. 1996; 30 : 390A-396A.

8. Gaskin DE, Ecology of whales and Dolphin. Heinemann, London and Exeter, New Hampshire, 1982. p. 459.

9. Tanabe S, Tatsukawa R, Maruyama K, Miyazaki N. Transplacental transfer of PCBs and chlorinated hydrocarbon pesticides from the pregnant striped dolphin (Stenella coeruleoalba) to her fetus. Agri. Biol. Chem. 1982; $46: 2569-$ 2578.

10. Wagemann R, Muir DCG. Concentrations of heavy metals and organochlorines in marine mammals of northern waters : Overview and evaluation. Conadian Technical Report of Fisheries and Aquatic Science No. 1269, Western Region, Department of Fisheries and Oceans, Canada.

11. Tanabe S, Subramanian AN, Ramesh A, Kumaran PL, Miyazaki N, Tatsukawa R. Persistent organochlorine residues in dolphins from Bay of
Bengal, South India. Mar. Pollut. Bull. 1993; 26 : $311-316$.

12. Tanabe $\mathrm{S}$, Mori $\mathrm{T}$, Tatsukawa $\mathrm{R}$, Miyazaki $\mathrm{N}$. 1983. Global pollution of marine mammals by PCBs, DDTs and HCHs. Chemosphere $1983 ; 12$ : $1269-1275$.

13. Tanabe S, Miura S, Tatsukawa R. Variation of organochlorines with age and sex in Antarctic Minke whale. Mem. Natl. Inst. Polar Res. 196; 44:174- 181.

14. Subramanian AN, Tanabe $S$, Fujise $Y$, Tatsukawa $\mathbf{R}$, Organochlorine residues in Dall's and True's porpoises collected from Northwestern Pacific and adjacent waters. Mem. Natl. Inst. Plar. Res.1986; $44: 167-173$.

15. Subramanian AN, Tanabe $S$, Tatsukawa $R$, Estimating some biological parameters of Baird's beaked whales using PCBs and DDE as tracers. Mar. Pollut. Bull. 1988; 6 : $284-287$.

16. Kasuya T, Jones LL. Behaviour and segregation of the Dall's porpoise in northwestern North Pacific Ocean. Sci. Rep. Whales Res. Inst.1984; 35:107-128.

17. Kasuya T, Shiraga S. Growth of Dall's porpoises in the western North Pacific and suggested gerographical growth differentiation. Sci. Rep. Whales Res. Inst. 1985; 36 : $139-152$.

18. Tanabe S, Loganathan BG, Subramanian AN, Tatsukawa, R, Organochlorine residues in Short finned pilot whale. Possible use as tracers in biological parameters. Mar. Pollut. Bull. 1987 ; 18 : $561-563$

19. Minh TB, Prudente MS, Watanabe M, Tanabe $S$, Nakata H, Miyazaki N, Gefferson, TA, Subramanian AN. Recent contamination of persistent chlorinated endocrine disrupters in cetaceans from the North Pacific and Asian coastal waters. Water Sci. Technol. 2000; $42: 231-241$.

20. Prudente $M$, Tanabe $S$, Watnabe $M$, Subramanian AN, Miyazaki N, Suarez $P$, Tatsukawa R. Organochlorine contamination in some odontoceti species from the North Pacific and Indian Ocean. Mar. Environ. Res. 1997; $4: 415$ - 427.

21. Prudente $M$, Tanabe $S$, Watanabe $M$, Takahashi $S$, Iwata $\mathrm{H}$, Miyazaki N, Subramanian AN. Butyltin and organochlorine contamination in marine mammals from the North Pacific and Asian coastal waters. In Proc. Internatl. Symp. on West Pacific, Okinawa, Japan. Held on Feb. 2-3, 1998. 